\title{
The challenge of perioperative pain management in opioid-tolerant patients
}

\author{
This article was published in the following Dove Press journal: \\ Therapeutics and Clinical Risk Management \\ 5 September 2017 \\ Number of times this article has been viewed
}

\section{Flaminia Coluzzi' \\ Francesca Bifulco ${ }^{2}$ \\ Arturo Cuomo² \\ Mario Dauri ${ }^{3}$ \\ Claudio Leonardi ${ }^{4}$ \\ Rita Maria Melotti ${ }^{5}$ \\ Silvia Natoli ${ }^{3}$ \\ Patrizia Romualdi ${ }^{6}$ \\ Gennaro Savoia ${ }^{7}$ \\ Antonio Corcione ${ }^{8}$}

'Department of Medical and Surgical Sciences and Biotechnologies, Unit of Anaesthesia, Intensive Care and Pain Medicine, Sapienza University of Rome, Polo Pontino, Latina, ${ }^{2}$ National Cancer Institute "G Pascale"

Foundation, Unit of Anaesthesia, Intensive Care and Pain Medicine, Naples, ${ }^{3}$ Department of Clinical Science and Translational Medicine, Tor Vergata University of Rome, ${ }^{4}$ Addiction Disease Department, Local Health Unit (ASL) Rome 2, Rome, ${ }^{5}$ Department of Medical and Surgical Sciences, ${ }^{6}$ Department of Pharmacy and Biotechnology, Alma Mater Studiorum University of Bologna, Bologna, ' Department Anesthesia, Fatebenefratelli Hospital, Naples, ${ }^{8}$ Unit of Anaesthesia and Intensive Care, Dei Colli Hospital,V. Monaldi, Naples, Italy

Correspondence: Flaminia Coluzzi Department of Medical and Surgical Sciences and Biotechnologies, Unit of Anaesthesia, Intensive Care and Pain Medicine, Sapienza University of Rome, Polo Pontino, Corso della Repubblica, 79, 04I 00 Latina, Italy

Tel +397736513334

Fax +397736513315

Email flaminia.coluzzi@uniromal.it

\begin{abstract}
The increasing number of opioid users among chronic pain patients, and opioid abusers among the general population, makes perioperative pain management challenging for health care professionals. Anesthesiologists, surgeons, and nurses should be familiar with some pharmacological phenomena which are typical of opioid users and abusers, such as tolerance, physical dependence, hyperalgesia, and addiction. Inadequate pain management is very common in these patients, due to common prejudices and fears. The target of preoperative evaluation is to identify comorbidities and risk factors and recognize signs and symptoms of opioid abuse and opioid withdrawal. Clinicians are encouraged to plan perioperative pain medications and to refer these patients to psychiatrists and addiction specialists for their evaluation. The aim of this review was to give practical suggestions for perioperative management of surgical opioidtolerant patients, together with schemes of opioid conversion for chronic pain patients assuming oral or transdermal opioids, and patients under maintenance programs with methadone, buprenorphine, or naltrexone.
\end{abstract}

Keywords: opioids, postoperative pain, addiction, abusers, buprenorphine, methadone

\section{Introduction}

Perioperative management of patients who have been exposed to long-term opioids, whether of therapeutic or recreational origin, is a challenging issue for anesthesiologists. This population is increasing, because in most developed countries, the number of patients for whom opioids are prescribed on a long-term basis has grown rapidly over the last decade. In the USA, sales of prescription opioids have quadrupled in the last 15 years, leading to one out of five patients with chronic nonmalignant pain being under treatment with opioids. ${ }^{1}$ The wide use of these drugs has led to an increase in prescribed opioid abusers, estimated to be nearly 2 million in the USA. Over 90 Americans die every day from an opioid overdose. The opiates commonly abused include prescription opioids, being oxycodone and hydrocodone, which are most commonly involved in overdose death; illicit drugs like heroin; and de-addiction opioids like methadone and buprenorphine. ${ }^{2}$

Conversely, European countries are still far away from the prescription opioid market that is observed in the USA. ${ }^{3}$ Therefore, nowadays, the prevalence of opioid abusers among chronic pain patients seems to be significantly lower in Europe, compared with the USA; however, the risk cannot be excluded. ${ }^{4}$ According to the European Drug Report 2016, in Europe in 2014, the average prevalence of high-risk opioid users among adults (aged 15-64 years) was estimated at $0.4 \%$, the equivalent of 1.3 million. Opioids have been found in $82 \%$ of fatal overdoses, mostly in the north of Europe, probably related to an increase in new heroin uptake and changing 
drug consumption patterns, particularly the increased use of synthetic opioids. ${ }^{5,6}$ According to the European Monitoring Centre for Drugs and Drug Addiction, high-risk drug use includes any "drug use that is causing actual harms (negative consequences) to the person (including dependence, but also other health, psychological or social problems) or is placing the person at a high probability/risk of suffering such harms." In Italy, in 2014, the latest estimate suggested that there were 203,000 high-risk drug users, corresponding to a rate of 5.16 per 1,000 inhabitants aged 15-64 years and over 75,000 clients in a substitution treatment. A decline in the estimated number of high-risk opioid users that was noted from 2008 onwards stopped in 2014, when a noticeable increase was seen. ${ }^{7}$

These epidemiological data explain why anesthesiologists, surgeons, and all health care professionals (HCPs) involved in perioperative management are likely to encounter with increasing probability in their clinical practice opioid users and abusers who require surgical treatment and adequate perioperative analgesia. Opioids are the mainstay of an effective analgesia after surgery, for the management of moderate to severe pain, along with regional techniques. ${ }^{8}$ However, their use may result in being extremely challenging in these patients.

The aim of this narrative review was to give a clinical perspective of the perioperative management of opioidtolerant patients.

\section{Tolerance, physical dependence, hyperalgesia, and addiction to opiates}

Our first suggestion for HCPs is to be familiar with some pharmacological phenomena that are typical of the opioid treatment.

Tolerance and physical dependence can happen after chronic exposure to many drugs, including opiates. Tolerance is the decrease of the pharmacological effect occurring after repeated administration of opioid receptor agonists, that is, the body adapts to the drug and requires increased doses to achieve a certain effect. ${ }^{9}$

These changes in body homeostasis lead to physical dependence, a state of neuro-adaption to a specific opioid, characterized by the withdrawal crisis if the agonist administration is abruptly discontinued. These two phenomena are therefore related to each other and independent from the psychic dependence, also named addiction, but often accompany it.

It is now believed that neuronal adaptation phenomena to the chronic effects of opiates occur, involving a complex series of molecular and cellular events, including receptor desensitization, downregulation, and internalization. ${ }^{9}$

Conversely, drug addiction is defined as a chronic, relapsing brain disease, characterized by compulsive illegal drug seeking and use, despite harmful consequences. ${ }^{10}$ Biological/ genetic and environmental factors may increase the vulnerability to addiction, particularly in early adolescence. ${ }^{11}$

A therapeutically appropriate use of opiates for the treatment of chronic pain has been hindered to date by the incorrect belief that their use will inevitably lead to the psychic dependence. The actual prevailing hypothesis suggests that the therapeutic use of opiates does not affect the conditioning environmental stimuli, which are so important in determining the positive reinforcement that leads to the compulsive use. The condition in which the drug is taken, and especially the underlying painful disease, do not provide the substrate and the context in which the patient seeks for the drug; clinical findings in the field of pain confirm that the phenomenon of abuse is observed very rarely., ${ }^{42}$ Recent neurobiological studies in animal models suffering from neuropathic pain and treated with opioids showed a decrease in dopamine production and the "reward effect" typical of drug addiction. ${ }^{13}$

Opiates produce strong analgesia, but sometimes their use is limited by an increased paradoxical hypersensitivity, known as opioid-induced hyperalgesia (OIH), in some cases associated with tolerance. ${ }^{14}$ Cellular and molecular mechanisms underlying $\mathrm{OIH}$ include genetic differences, variants of mu opioid receptor (MOR), neurons and glia factors, long-term potentiation, neuronal sensitization, and neuroinflammation. Recently, it has been proposed that epigenetic mechanisms, such as DNA hyper-methylation and histone deacetylases, might be responsible for $\mathrm{OIH}$, leading to a novel approach in pain therapy by means of drugs acting on epigenetic targets, such as L-acetylcarnitine. ${ }^{14}$

\section{Preoperative evaluation and identification of population at risk}

During preoperative evaluation, anesthesiologists, in their practice, are likely to encounter an increasing number of opioid users and abusers, which presents a wide array of challenges. The main value of preoperative assessment is the opportunity for anesthesiologists to identify risk factors and reduce the patients' surgical and anesthetic perioperative morbidity or mortality. ${ }^{15}$

A few key points are essential for preoperative management of these subjects:

1. Always consider this key question: "Is my patient an opioid user or abuser?" 
Table I Clinical differentiation between opioid users for chronic pain and opioid abusers

\begin{tabular}{|c|c|c|}
\hline & $\begin{array}{l}\text { Opioid users for } \\
\text { chronic pain }\end{array}$ & Opioid abusers \\
\hline \multirow[t]{2}{*}{ Use of opioids } & Appropriate & Out of control \\
\hline & Declared & Often deliberately omitted \\
\hline Quality of life & Improved by opioids & Impaired by opioids \\
\hline $\begin{array}{l}\text { Awareness of opioid- } \\
\text { related side effects }\end{array}$ & Complete & Unconcerned \\
\hline Diagnosis & Available & Unavailable \\
\hline $\begin{array}{l}\text { Treatment plan and } \\
\text { medical prescription }\end{array}$ & Followed & Unavailable \\
\hline Opioid medication & Available & Hidden, illicit \\
\hline
\end{tabular}

True abusers should be promptly detected, while opioid users should not be wrongly labeled as addicted. Table 1 may help anesthesiologists to detect the clinical differentiation of opioid-dependent patients, between opioid users for chronic pain and opioid abusers. ${ }^{16}$

2. In opioid users/abusers obtain details of the type of opioid, the duration of use/abuse, and the timing of the last dose. ${ }^{17}$

Patients suffering from opioid addiction may give false history during pre-anesthetic check-up. Particularly, anesthesiologists should consider their privacy and the reluctance to speak in front of their parents, for young people.

Not all opioids have the same abuse potential, depending on their ability to release dopamine from the nucleus accumbens, and pharmacokinetics (PKs). ${ }^{18} \mathrm{Imme}-$ diate release formulations may have a higher risk.

3. Recognize signs and symptoms of opioid abuse and opioid withdrawal as soon as possible (Table 2).

Consider time of the last dose. Withdrawal symptoms will occur upon abrupt discontinuation of opioids or when opioid antagonists are administered. Acute withdrawal timeframes vary for specific substances, according to their

Table 2 Signs and symptoms of opioid abuse and opioid withdrawal

\begin{tabular}{ll}
\hline Opioid abuse & Opioid withdrawal \\
\hline Vomiting & Dysphoric mood \\
Pruritus & Nausea or vomiting \\
Sweating & Lacrimation \\
Twitching & Rhinorrhea \\
Miosis (contracted pupils) & Muscle aches \\
Loss of appetite & Pupillary dilation \\
Drowsiness & Piloerection \\
Respiratory depression & Sweating \\
Coma & Diarrhea \\
Needle marks & Yawning \\
& Fever \\
\hline
\end{tabular}

PKs: 6-18 hours for morphine and heroine; $24-48$ hours for methadone. Protracted or chronic withdrawal refers to the presence of symptoms that persist beyond the generally expected acute withdrawal, probably caused by adaptive changes in the central nervous system (CNS) that lead to affective changes. For elective surgery, opioid users should be encouraged to take their usual dose of prescribed opioid on the morning of surgery.

4. Identify population at risk.

Unfortunately, patients may deliberately omit to declare the use of opioids. Identifying opioid-consuming patients is essential for their adequate perioperative management. Different tools have been proposed for identifying potential opioid abusers, particularly for subjects suffering from chronic pain, at the beginning of treatment with opioid analgesics, but no one has been conceived to identify the evaluation of indirect factors of drug abuse. ${ }^{19}$ The Addiction Risk Questionnaire has been proposed as a 28 -item tool, specifically designed for the detection of patients with high measurable score of vulnerability to drug addiction. ${ }^{20}$ Nicotine addiction, alcohol dependence, and psychiatric history are significantly considered the most relevant risk factors. Preoperative opioid use has been associated with a potentially increased risk for opioid misuse after surgery. ${ }^{21}$ Therefore, this vulnerable patient population may require a closer follow-up and early referral to appropriate specialists when needed.

5. Obtain comprehensive assessment including history, physical examination, and review diagnostic studies.

Patients with opioid abuse and dependence undergoing elective surgery have increased risk of postoperative mortality and morbidity, including surgical site infections, mental disorders, respiratory failure, pneumonia, mechanical ventilation, myocardial infarction, and gastrointestinal events. Preoperative opioid misuse was also associated with prolonged hospital length of stay and increased resource utilization. ${ }^{22}$

6. Evaluate common comorbidities in addicted patients. ${ }^{23}$

- Cardiovascular disease: hypertension, dilated cardiomyopathy.

- Gastrointestinal disease: reduced gastrointestinal motility, gastroesophageal reflux disease (GERD), which increases the risk of aspiration during orotracheal intubation, dysphagia, constipation, and bowel discomfort.

- Infectious disease: hepatitis, human immunodeficiency virus, sexually transmitted disease.

- Difficult vein access. 
- Concomitant drug abuse (anxiolytics, benzodiazepines, alcohol).

7. Consider possible coexisting psychiatric disorders (depression, anxiety, psychosis, and personality disorders). ${ }^{24}$

Some patients with complicating medical and social conditions may require integrated care with behavioral health specialists. Consider referral to psychiatrists and addiction specialists for their evaluation.

8. Avoid prejudices and assure the patient.

9. Keep in mind patients' fears.

Opioid-dependent patients may fear the risks of under-treatment due to prejudices, dependence relapse, and ability self-administering analgesia by patient-controlled analgesia (PCA). Consider patients' expectations related to postoperative pain management, and investigate the possible correlation with previous experiences. Patients should be reassured that despite a previous or an ongoing history of opioid dependency, effective pain control is an achievable goal. Risk of relapses can be minimized.

10. Plan perioperative pain medication.

- Investigate effective management strategies used in previous procedures.

- Consider acetaminophen, non-steroidal antiinflammatory drugs (NSAIDs) or selective COX-2 inhibitors as preoperative medication.

- Discuss with the patient the analgesic strategy (multimodal approach, regional techniques when suitable, PCA).

- Document treatment plan with a written opioid pain care agreement with the patient. ${ }^{25}$

\section{Prejudice and misconceptions that limit postoperative pain treatment in opioid-tolerant patients}

Patients on chronic opioids are at risk of receiving inadequate analgesia because of clinicians' misconceptions about opioids or prejudice toward patients addicted to opioids. ${ }^{26}$

Recent warning on the risk of abuse among opioid users in chronic non-cancer pain, including the Center for Disease Control and individual state guidelines, have generated a sort of opiophobia. Addiction is commonly perceived as a crime rather than a disease; therefore, these patients are stigmatized for their opioid use. Consequently, when asked for more opioids to relieve pain, they are seen under suspicion and perceived as drug-seeking. These patients are more demanding than others because of fear that their pain will be under-treated or their opioid therapy be discontinued causing a withdrawal syndrome. ${ }^{27} \mathrm{HCPs}$ often perceive these patients as manipulative. ${ }^{28}$ It is important, then, to distinguish between addiction and pseudo-addiction. A careful clinical assessment for objective evidence of pain can decrease the risk of being manipulated.

Four common misconceptions of HCPs may result in under-treatment of postoperative pain: ${ }^{26}$

1. Maintenance therapy with buprenorphine or methadone provides analgesia.

Patients on maintenance therapy with an opioid agonist require an additional opioid dose for the following reasons:

- Methadone and buprenorphine effect on pain suppression is shorter (4-8 hours) than the duration of their effect on opioid withdrawal (24-48 hours). ${ }^{17}$

- Due to opioid cross-tolerance, patients require higher and more frequent doses of opioid analgesics to achieve adequate analgesia. ${ }^{29}$

- OIH may counteract the analgesic effects of opioids. ${ }^{30}$

- These patients display increased sensitivity to natural and experimental pain. Consequently, pain scores are usually higher and decrease more slowly. ${ }^{31,32}$

2. Additional opioids for analgesia may cause addiction relapse.

There is no evidence that analgesic opioids will exacerbate addictive disease. Two small studies suggest that patients on maintenance methadone programs receiving opioids, either for cancer pain ${ }^{33}$ or for post-surgical pain, ${ }^{34}$ showed no relapse when matched with patients receiving maintenance methadone therapy only. Conversely, due to the potential stress induced, unrelieved pain is a risk factor for relapse among the addicted patients..$^{35,36}$

3. Additional opioids for analgesia may cause respiratory and CNS depression.

Clinical experience does not support this concern. Conversely, there is evidence that tolerance to opioidrelated respiratory and CNS depression is protective in acute or worsening chronic pain. Typically, cancer patients who require additional opioids do not exhibit drug toxicity when the dose is escalated. Moreover, inpatients' response to opioids can be monitored. ${ }^{37}$

4. PCA is inadequate for post-surgery analgesia in opioidtolerant patients.

There are no specific guidelines available to address pain-relief interventions in this specific population. Nonetheless, a multimodal approach is recommended. ${ }^{38}$ 
When regional analgesia is not applicable, a PCA system can be considered especially for those who are unable to maintain their oral opioids in the perioperative period. ${ }^{39}$ Pain scores in opioid-tolerant patients are higher and decrease more slowly. Opioid tolerance significantly affects analgesic requirements. Unrelieved pain is a risk factor for relapse among patients recovering from abuse. PCA is the only system which allows to provide patients with the right dose of opioid, according to their effective needs. ${ }^{40}$ However, the appropriate setting of bolus size and lockout interval may be challenging ${ }^{41}$ despite the risk of opioid-related respiratory depression being low in opioid-tolerant patients.

\section{Perioperative management of opioid users for chronic pain}

Perioperative management of patients taking opioid therapy for chronic pain is very challenging for anesthesiologists. This population is at a very high risk of suffering severe postoperative pain. Limited application of guidelines in real life can be one of the reasons for the high incidence of uncontrolled postoperative pain. ${ }^{42}$

Inadequate postoperative pain management may increase pulmonary and cardiovascular complications as well as hospital length of stay. ${ }^{43,44}$ Adequate perioperative management is directed to reduce patients' perioperative anxiety as well as postoperative and chronic pain.

Nowadays, evidence on perioperative management of opioid users is lacking. Therefore, most information comes from expert opinions, more than from clinical trials.

\section{How to treat patients taking oral opioids for chronic pain management}

In patients taking opioids, when significant pain can be anticipated, such as after elective surgery, it is helpful planning in advance a pain treatment and documenting this plan in the medical record, as resumed in the IDEAL five steps (Table 3).

It is well recognized that patients should take their usual dose of oral opioid on the morning of surgery, with preoperative administration of their daily maintenance or baseline opioid dose before induction of general, spinal, or regional anesthesia.

If the patient cannot receive oral intake (preoperative fasting), the oral opioid dose can be converted to the corresponding intravenous (IV) dose of morphine:
Table 3 Perioperative treatment plan for opioid-tolerant patients

\begin{tabular}{ll}
\hline D Identify the problem and specific risk factors \\
Define a plan of perioperative pain management, involving \\
anesthesiologists, surgeons, nurses, and family members \\
Explore possible strategies: use multimodal analgesia and \\
regional techniques, when applicable
\end{tabular}

- Determine the total 24-hour dose of the current oral opioid.

- Calculate the oral morphine equivalent dose (MED) of the current opioid, by using equianalgesic tables (Table 4).

- Convert the calculated oral MED in IV dose of hydrochloride morphine, according to the oral:IV ratio for morphine of 3:1.

Opioid rotation allows to reduce the dose by $50 \%$ and titrate it according to the patient response (the equianalgesic dose could be lower than expected because of incomplete cross-tolerance). ${ }^{45,46}$ For example: In a patient taking oral oxycodone at $40 \mathrm{mg}$ daily, the equianalgesic oral dose of morphine would be $60 \mathrm{mg}$ daily, and the IV dose of morphine sulfate would be $20 \mathrm{mg}$ daily (ie, continuous infusion of $0.8 \mathrm{mg} / \mathrm{h}$ per 24 hours).

In patients taking the oral combination oxycodone/ naloxone in a ratio $2: 1$, the effect of the opioid antagonist is limited to the gastrointestinal tract, as most of naloxone undergoes first pass metabolism in the liver; therefore, only $2 \%$ remains available in the CNS, without any effect on analgesia. Also in these patients, the usual oral dose can be perioperatively administered if possible. This formulation has also been used as postoperative pain treatment in orthopedic surgery. ${ }^{47}$

\section{Intraoperative management}

There are no data suggesting the preference for a specific intraoperative opioid over another in patients chronically treated with opioids or addicted..$^{48}$ It is impossible to predict the level of intraoperative tolerance. The anesthesiologist responsible for the patient may select the opioid and titrate the doses following the usual method. Usually a parenteral infusion is used. The use of remifentanil is controversial because of possible acute development of tolerance and hyperalgesia. ${ }^{49}$ Dosage and requirements in different surgical settings should be guided by vital signs (heart rate, pupil dilation, arterial blood pressure) and, most recently, by analgesia nociception index monitoring. ${ }^{50}$ Usually these 
Table 4 Equianalgesic doses of opioids

\begin{tabular}{|c|c|c|c|c|}
\hline Opioid & $\begin{array}{l}\text { Approximate oral } \\
\text { equianalgesic dose }\end{array}$ & Onset & Duration & Half-life \\
\hline Morphine (reference drug)* & $30 \mathrm{mg}$ & $2-3 \mathrm{~h}$ & $8-12 \mathrm{~h}$ & $2-4 h$ \\
\hline Tramadol* & $150 \mathrm{mg}$ & $\mathrm{I}-2 \mathrm{~h}$ & $8-12 \mathrm{~h}$ & $2-4 h$ \\
\hline Codeine (with APAP) & $200 \mathrm{mg}$ & $30-60 \mathrm{~min}$ & $4-8 \mathrm{~h}$ & $3-4 h$ \\
\hline Oxycodone* & $20 \mathrm{mg}$ & $\mathrm{I}-2 \mathrm{~h}$ & $6-10 \mathrm{~h}$ & $3-4 h$ \\
\hline Tapentadol* & $100 \mathrm{mg}$ & $\mathrm{I}-2 \mathrm{~h}$ & $8-12 \mathrm{~h}$ & $2-4 h$ \\
\hline Hydromorphone ${ }^{\#}$ & $7.5 \mathrm{mg}$ & $12-14 \mathrm{~h}$ & $20-24 \mathrm{~h}$ & $8-16 h$ \\
\hline Oxymorphone & $10 \mathrm{mg}$ & $30-45 \mathrm{~min}$ & $4-6 \mathrm{~h}$ & $2-3 \mathrm{~h}$ \\
\hline Hydrocodone (with APAP, ASA, or ibuprofen) & $30 \mathrm{mg}$ & $15-30 \mathrm{~min}$ & $4-8 \mathrm{~h}$ & $2-3 h$ \\
\hline
\end{tabular}

Notes: *PKs (pharmacokinetics) refer to slow release twice daily (BID) formulations. "PKs refer to once daily hydromorphone formulation.

Abbreviations: APAP, acetaminophen; ASA, acetylsalicylic acid.

patients need a larger dose of opioids than those commonly used for adequate pain control in opioid-naïve patients. ${ }^{51,52}$ Regional analgesia may be helpful to reduce intraoperative opioid requirements, but does not provide the elimination of withdrawal symptoms. Also wound infiltration with local anesthetics should be considered. Low dose of ketamine (subanesthetic dose) can lead to improved pain scores and reduced opioid consumption. ${ }^{16}$

\section{Postoperative pain}

Several studies demonstrated that opioid-dependent patients have four-fold increased opioid requirements in the postoperative period compared with opioid-naïve patients. Chronic opioid users for malignant pain have been reported to use three times more epidural morphine and five times more IV morphine for breakthrough pain in the postoperative period to experience full pain control. Moreover, the duration of postoperative treatment is about three times longer in these patients compared with opioid-naïve patients. ${ }^{52}$

Multimodal analgesia is mandatory to reduce opioid consumption. Regional analgesia may be useful; however, anesthesiologists should consider baseline opioid requirements to avoid withdrawal symptoms. PCA may be helpful to minimize the risk of under-medication and breakthrough pain and to provide equivalent baseline preoperative opioid dose. ${ }^{16}$ There are many advantages in using the PCA system: it is easy and immediate to use, provides stable plasma levels, ensures pain relief with a lower total opioid consumption, allows fewer interactions between patient and HCPs, avoiding anxiety, prejudices and acute withdrawal episodes. ${ }^{48}$ A few limitations are present: PCA boluses may be used for psychological effects (abuse), and frequent requested doses could be perceived as drug craving by HCPs.

Opioid antagonists, including naloxone and naltrexone, in opioid users should be avoided. Their use, as well as the use of mixed agonist-antagonist-type opioids such as nalbuphine, butorphanol, and pentazocine could precipitate withdrawal symptoms. These drugs may precipitate acute opioid withdrawal in these individuals.

\section{How to treat patients taking transdermal opioids for chronic pain management}

The most commonly used transdermal opioids are fentanyl patch (lasting 72 hours) and buprenorphine patch (available in two formulations: at higher doses - from $35 \mu \mathrm{g} / \mathrm{h}$, lasting 72 hours, and at lower doses - from 5 to $20 \mu \mathrm{g} / \mathrm{h}$, lasting 1 week).

The efficacy of full opioid agonists (used for surgical pain) could be reduced by the presence of buprenorphine. Therefore, if the acute pain episode is anticipated (ie, postoperative pain after elective surgery), buprenorphine should be discontinued 72 hours prior to surgery and conversion to a full agonist can be achieved preoperatively. ${ }^{17}$

If the acute pain is unanticipated (eg, from trauma) and it is not possible to discontinue the buprenorphine, we suggest using an intravenous opioid agonist that binds strongly to MOR, such as fentanyl and sufentanil. Higher doses of opioids may be necessary to overcome the buprenorphine occupation of receptors; hence, very close perioperative monitoring is required. The patient will then be discharged on full opioid agonist for the control of pain. Reconversion to buprenorphine therapy will be done after discharge by the pain specialist. ${ }^{17}$

Conversely, transdermal fentanyl patch should be maintained during the surgery. In case this preparation is removed, a new patch may then be applied intraoperatively. ${ }^{17}$ However, HCPs should consider that it may take 6-12 hours to reestablish baseline analgesia; therefore, a baseline IV fentanyl infusion may be initiated to maintain plasma concentrations. ${ }^{16}$ The only concern about transdermal fentanyl patch is related to the risk of altered absorption depending on the type of 
surgery, amount of administered fluids, and skin temperature during the procedure. Hypothermia or rewarming may affect the kinetics of transdermal fentanyl. Therefore, in the case of major surgery, it is preferable to remove the fentanyl patch and to administer an equipotent dose of morphine as a substitute. ${ }^{48}$ For example: In a patient taking transdermal fentanyl at $25 \mu \mathrm{g} / \mathrm{h}$ (patch change every 72 hours), the equianalgesic oral dose of morphine would be $60 \mathrm{mg}$ daily, and the IV dose of morphine sulfate would be $20 \mathrm{mg}$ daily (ie, continuous infusion of $0.8 \mathrm{mg} / \mathrm{h}$ per 24 hours).

\section{How to treat patients taking intrathecal opioids for chronic pain management}

Presence of invasive pain treatment devices (eg, intrathecal pumps, spinal cord stimulators) should be investigated as additional information in patients with chronic cancer or non-cancer pain..$^{53}$

Continuous epidural and intrathecal opioid infusions, delivered by internally implanted devices, can be maintained during the surgery as a baseline requirement, compatible with the kind of surgery. Caution should be taken if undertaking a central block or a surgical procedure near the neuroaxial device. Obviously, in the case of spine surgery, it is reasonable to prescribe the patient with an equivalent dose of IV morphine, to guarantee background analgesia for chronic pain management.

\section{Perioperative management of opioid abusers}

In 2016, the American Pain Society (APS) released new guidelines for postsurgical pain management, which encourage an interdisciplinary approach with routine use of nonpharmacological therapies and nonopioid medications into multimodal analgesia regimens. When a patient has opioid tolerance, or a history of substance abuse or addiction, APS guidelines recommend to consult a pain management specialist. Adequate pain treatment should not be withheld from patients with active or previous opioid addiction because of fears of worsening addiction or precipitation of relapse. $^{8}$

It is important to distinguish clinically between abusers, former abusers, and abusers in pharmacological treatment with methadone, buprenorphine, or naltrexone.

For abusers, the major problem is related in identifying the exact street dose of the abused drugs or other adjuvants, to convert these doses to morphine or methadone basal daily dose for maintenance during the perioperative phase.
It is important to obtain as much information about an individual's dependence as possible. Stromer et al suggest a basal equivalence between $1 \mathrm{~g}$ of heroin and 40-80 $\mathrm{mg}$ of methadone. $^{49}$

For former abusers under maintenance treatment programs, anesthesiologists should be aware of the drug therapy and the timing of the last dose, in order to plan adequate perioperative management. Theoretically, any longacting oral opioid could be used in the opioid maintenance approach, as the goals are to reduce the infective risks of IV injections, to decrease craving and rewarding effects, and to reduce crimes related to the use of illicit drugs. ${ }^{54} \mathrm{In}$ clinical practice, the two most used drugs are methadone and buprenorphine, along with naltrexone.

\section{How to manage patients under maintenance methadone treatment?}

Methadone is a synthetic opioid agonist and N-metyl-Daspartate receptor antagonist, which has been used to treat opioid dependence since the 1950s.

Methadone is dosed daily in methadone maintenance treatment (MMT) because after oral administration, the elimination half-life averages $15-40$ hours and its activity is significantly longer than most other opioids. ${ }^{55}$ By comparison, the short-acting heroin (3-6 hours) requires several injections during the day while, in MMT, methadone is administered only once a day. Conversely, when used for managing acute pain, methadone must be dosed TID to QID to adequately provide analgesia. $^{26}$

The maintenance dose of oral methadone begins with initial oral doses of $15-30 \mathrm{mg}$, usually increased to the most effective dose between 80 and $120 \mathrm{mg}$ daily. Long-term use of MMT dramatically reduces opiate abuse patterns.

Perioperative recommendations for patients in MMT include: ${ }^{26}$

1. If the patient can receive oral intake, he or she should continue taking oral methadone on the morning of surgery and through all the perioperative period.

2. If the patient is not able to receive oral intake, the methadone dose can be given parenterally (intramuscular or subcutaneous) at a dose half to two thirds the maintenance dose divided into two to four equal doses a day.

The relative analgesic potency ratio of oral to parenteral methadone is $2: 1$, with wide interindividual variability due to pharmacodynamic and PK properties. ${ }^{8,54}$ For example: In a patient taking oral methadone at $80 \mathrm{mg}$ daily, the intramuscular dose would be $10-13 \mathrm{mg}$ every 6 hours or 20-26 mg every 12 hours. 
3. If methadone is not available in your hospital, you should know practical rules to convert methadone to morphine.

Unfortunately, methadone conversion is challenging for prescribers, because conversion calculations may not be bidirectional (ie, the morphine-to-methadone conversion ratio may not be the same as the methadone-to morphine ratio). As the half-life of methadone is very long, 15-40 hours, it stays in the body for several days after discontinuation. Moreover, because methadone is metabolized by CYP450, PK parameters and polymorphism of CYP450 may result in large interpatient variability in the equianalgesic conversion ratio and huge half-life variation (up to 150 hours) ${ }^{56}$ Finally, some drugs such as antidepressants (selective serotonine reuptake inhibitors [SSRIs], amitriptyline), antifungals (fluconazole, ketoconazole), and macrolide antibiotics (erythromycin, clarithromycin) may increase methadone concentrations, by inhibiting CYP3A4 metabolism. Conversely, other drugs such as antiepileptics (carbamazepine, phenobarbital, phenytoin), antipsychotics (risperidone), antiretrovirals (nevirapine, ritonavir), anitubercular (rifampin) may decrease methadone concentrations. ${ }^{57}$ Most studies investigated the conversion dose ratio in patients being prescribed in the opposite manner, that is, from morphine to oral methadone, showing that methadone is more potent in patients on high-dose opiates. When converting from high doses of opiates to methadone, less methadone will be required. Conversely, changing from methadone to other opioids is still an area of limited research but of increasing importance. The estimated dose ratio for IV methadone to oral MED is 13.5. The estimated dose ratio for oral methadone to oral MED is 4.7. When oral methadone is converted to IV morphine sulfate, the estimated dose ratio is $2: 1$. This difference between IV and oral methadone, in terms of MED, is not expected based on methadone's high oral bioavailability, but it appears to be clinically important and likely due to presystemic (first pass) elimination. However, this ratio may hugely vary depending on patient metabolism. Carefully titrate the new opioid, after rotation. Usually 2-3 days are required to achieve a stable dose. Reassess patients at appropriate intervals. ${ }^{58}$ For example: In a patient taking oral methadone at $80 \mathrm{mg}$ daily, the equivalent IV dose of morphine would be $40 \mathrm{mg}$ daily. In opioid-naïve patients, the IV morphine dose can be reduced to $20-30 \mathrm{mg}$ daily (ie, continuous infusion of $1 \mathrm{mg} / \mathrm{h}$ or $24 \mathrm{mg}$ per 24 hours), only for maintenance therapy. Further doses of morphine are required for analgesia.

\section{How to manage patients under maintenance buprenorphine treatment?}

Buprenorphine has been considered as a partial $\mu$-agonist (or a mixed agonist-antagonist) and kappa-antagonist with a limited maximum effect (ceiling effect), but other evidence suggests that high doses of buprenorphine bind to nociceptin receptor (NOP).$^{59}$ It is used transdermally for chronic pain management and sublingually for long-term substitution in opioid abusers. Its effect is estimated from 24 to $>36$ hours; therefore, in maintenance programs, buprenorphine is dosed once a day or three times a week at a higher dose. The initial daily dose of $2-8 \mathrm{mg}$ is increased up to $4 \mathrm{mg}$ each week, up to a daily dose as high as $32 \mathrm{mg} .{ }^{.4}$

Available formulations for maintenance programs are:

- Sublingual buprenorphine tablets up to $32 \mathrm{mg}$ as a single daily dose.

- Buprenorphine/naloxone (sublingual tablets) up to $24 \mathrm{mg} /$ $6 \mathrm{mg}$ as a single daily dose.

When the combination buprenorphine/naloxone in a 4:1 ratio is taken sublingually, the opioid antagonist does not block the central effect of buprenorphine, because oral or sublingual naloxone, as previously described, is rapidly inactivated by the liver and its bioavailability results are very low. ${ }^{60}$

There are several possible approaches for treating severe acute pain that requires opioid analgesia in patients under buprenorphine maintenance treatment (BMT): 26,61

1. We suggest, as a first choice, to continue buprenorphine for the BMT and to use a different opioid for analgesia, by titrating an oral short-acting (immediate release [IR] morphine or oxycodone) or IV opioid analgesic (morphine or fentanyl) to the desired analgesic effect (continuous infusions are not recommended). Consider that higher doses of opioids could be necessary for competing with buprenorphine.

2. Alternatively, if a patient is taking a low maintenance dose of buprenorphine (eg, 2-8 $\mathrm{mg}$ per day), it can be used as analgesic itself. Administer the daily dose of the buprenorphine maintenance therapy or a higher dose, if necessary, given every 6-8 hours to take advantage of its analgesic properties, by increasing its plasma blood level. For example: In a patient taking buprenorphine at $32 \mathrm{mg}$ daily, the split dose would be $8 \mathrm{mg}$ every 6 hours (QID).

3. Only in patients who cannot be administrated sublingual formulations (facial trauma or unconscious patients), we propose to discontinue buprenorphine therapy $72 \mathrm{~h}$ before 
surgery and use standard opioids for titration of analgesia. Daily doses of opioids must be reassessed every day. Buprenorphine, indeed, will persist in the brain for the first 3-4 days and the dose of full opioid agonist could be higher than expected; while in the following days, the opioid dose could be decreased. For example: In a patient taking buprenorphine at $32 \mathrm{mg}$ daily, the starting IV dose of morphine could be up to $80 \mathrm{mg}$ daily by continuous infusion (up to $3 \mathrm{mg} / \mathrm{h}$ for 24 hours).

4. Finally, for major surgery, when postoperative pain is expected to be high and to require opioid therapy, consider that buprenorphine could act as an antagonist on MOR, due to its high affinity and its ceiling effect, and prevent the analgesic activity of the full opioid agonist. Moreover, buprenorphine has kappa opioid receptor antagonist activity that may interfere with the actions of other opioids. ${ }^{18}$

Therefore, if the risk for relapse is too high, we could suggest replacing buprenorphine with methadone a few days beforehand, with a ratio of about 1:5 (titrate methadone dose by increasing daily methadone doses of 10 to $20 \mathrm{mg}$ increments every 1-2 hours up to an adequate pain relief).

If time does not permit this conversion, due to unexpected events requiring opioid therapy (eg, accidents), titration of mu opioids agonist must be aggressive to provide sufficiently high doses to overcome the buprenorphine blockade. For example: In a patient taking buprenorphine at $32 \mathrm{mg}$ daily, the dose of oral methadone would be 120-150 $\mathrm{mg}$ daily (starting dose $40 \mathrm{mg}$ ) or intramuscular (IM) methadone $70-80 \mathrm{mg}$.

\section{How to manage patients under maintenance naltrexone treatment?}

Naltrexone is an opioid antagonist, used in alcoholdependent and opioid-dependent patients. Its efficacy is mediated through interactions between dopamine and the endogenous opioid neuropeptide systems, also involved in the expression of reinforcing effects of alcohol. The new once-monthly extended-release formulation of injectable naltrexone prevents the relapse to opioid dependence following detoxification. ${ }^{62}$

Few data are available on perioperative management of patients under maintenance naltrexone treatment. These patients represent a real challenge for anesthesiologists, because naltrexone may cause reduced sensitivity to opioids or precipitate withdrawal symptoms, when re-dosing naltrexone soon after opioid use. ${ }^{63}$ Based on the timing of their last naltrexone dose, patients may remain refractory or more sensitive to opioids. Within the first 2 weeks, they may continue to be refractory to opioid induced analgesia, whereas by the fourth week, the opioid receptor antagonism may be overcome by using larger doses of opioid agonist than in a typical patient. Sometimes, these patients may be more sensitive to opioids, because chronic opioid antagonism may result in an increased density of opioid receptors in the brain, and therefore, they may be more likely to develop the side effects and be at risk for significant respiratory depression.

Therefore, we suggest to mainly use nonopioid analgesics, such as NSAIDs and acetaminophen, corticosteroids, ketamine, and regional analgesic techniques, when indicated. Oral naltrexone should be discontinued at least 24-72 hours prior, if opioid-based anesthesia is planned. ${ }^{64}$ When the oncemonthly extended release formulation is used, we might suggest planning elective surgery during the fourth week, whereas in case of emergency, consider higher doses of opioids (identified by titration) and close clinical observation in the postoperative care unit for patients under maintenance naltrexone treatment.

\section{Conclusion}

The number of opioid-tolerant patients requiring acute pain treatment is increasing. The management of these patients in the perioperative period may be truly a challenge. This narrative review describes the view of a panel of experts on what the practicing clinicians (anesthesiologist, surgeon, or other HCPs) should know about the perioperative pain management of opioid-tolerant patients. Universal agreement on the management of these patients, particularly those under maintenance treatment, is lacking. A short list of key messages is reported as a Decalogue in the following box. The effective pain management of patients with an addictive disorder requires a comprehensive multidisciplinary approach that encompasses biological, pharmacological, social, and psychiatric aspects of a complex CNS disorder. Decalogue of good practice for perioperative pain management of opioid users and abusers:

1. Identify opioid user and abusers

2. Consider comorbidities

3. Consider the pharmacological and psychological differences present in such patients

4. Guarantee baseline requirements of opioids, regardless of the anesthetic technique

5. Prefer local and regional analgesia techniques when suitable 
6. Do not restrict opioid treatment in these patients

7. Provide effective analgesia and treat pain aggressively

8. Prefer multimodal analgesia

9. Do not induce weaning or $\mathrm{OIH}$ in the perioperative period

10. Do not give any unsuitable judgment regarding patient addiction.

\section{Disclosure}

The authors report no conflicts of interest in this work.

\section{References}

1. Dowell D, Haegerich TM, Chou R. CDC Guideline for prescribing opioids for chronic pain - United States, 2016. JAMA. 2016;315(15): 1624-1645.

2. Center for Disease Control. Prescription Opioid Overdose Data. Available from: https://www.cdc.gov/drugoverdose/data/overdose.html. Accessed April 2017.

3. Allegri M, Fanelli G. Opioids and chronic pain. Data from the "other side of the pond". Minerva Anestesiol. 2017;83(1):6-8.

4. Maremmani I, Gerra G, Ripamonti IC, et al. The prevention of analgesic opioids abuse: expert opinion. Eur Rev Med Pharmacol Sci. 2015; 19(21):4203-4206.

5. Thanki D, Vicente J. PDU (problem drug use) revision summary, February 20, 2013; European Monitoring Centre for Drugs and Drug Addiction. Available from: www.emcdda.europa.eu/publications. Accessed February 2017.

6. European Monitoring Centre for Drugs and Drug Addiction. European Drug Report 2016: Trends and Developments, Publications Office of the European Union, Luxembourg; 2016. Available from: www.emcdda. europa.eu/publications. Accessed February 2017.

7. European Monitoring Centre for Drugs and Drug Addiction. Statistical bulletin 2016; 2016. Available from: www.emcdda.europa.eu/data/ stats2016. Accessed February 2017.

8. Chou R, Gordon DB, de Leon-Casasola OA, et al. Management of postoperative pain: a clinical practice guideline from the American Pain Society, the American Society of Regional Anesthesia and Pain Medicine, and the American Society of Anesthesiologists' Committee on Regional Anesthesia, Executive Committee, and Administrative Council. J Pain. 2016;17(2):131-157.

9. Romualdi P, Candeletti S. The opioid system. In: Clementi F, Fumagalli G, editors. General and Molecular Pharmacology "Principles of drug action." NJ: Wiley; 2015:572-584.

10. Wise RA, Koob GF. The development and maintenance of drug addiction. Neuropsychopharmacology. 2014;39:254-262.

11. Squeglia LM, Cservenka A. Adolescence and drug use vulnerability: findings from neuroimaging. Curr Opin Behav Sci. 2017;13: 164-170.

12. Vadivelu N, Lumermann L, Zhu R, Kodumudi G, Elhassan AO, Kaye AD. Pain control in the presence of drug addiction. Curr Pain Headache Rep. 2016;20:35.

13. Niikura K, Narita M, Butelman ER, Kreek MJ, Suzuki T. Neuropathic and chronic pain stimuli downregulate central $\mu$-opioid and dopaminergic transmission. Trends Pharmacol Sci. 2010;31:299-305.

14. Roeckel LA, Le Coz GM, Gavériaux-RuffC, Simonin F. Opioid-induced hyperalgesia: cellular and molecular mechanisms. Neuroscience. 2016; 338:160-182.

15. Committee on Standards and Practice Parameters, Apfelbaum JL, Connis RT, Nickinovich DG; American Society of Anesthesiologists Task Force on Preanesthesia Evaluation, Pasternak LR, Arens JF, Caplan RA, et al. Practice advisory for preanesthesia evaluation: an updated report by the American Society of Anesthesiologists Task Force on Preanesthesia Evaluation. Anesthesiology. 2012;116(3):522-538.
16. Mitra S, Sinatra RS. Perioperative management of acute pain in the opioid-dependent patient. Anesthesiology. 2004;101:212-227.

17. Vadivelu N, Mitra S, Kaye AD, Urman RD. Perioperative analgesia and challenges in the drug-addicted and drug-dependent patient. Best Pract Res Clin Anaesthesiol. 2014;28:91-101.

18. Vander Weele CM, Porter-Stransky KA, Mabrouk OS, et al. Rapid dopamine transmission within the nucleus accumbens: dramatic difference between morphine and oxycodone delivery. Eur J Neurosci. 2014; 40(7):3041-3054.

19. Jamison RN, Serraillier J, Michna E. Assessment and treatment of abuse risk in opioid prescribing for chronic pain. Pain Res Treat. 2011;2011:941808.

20. Leonardi C, Vellucci R, Mammucari M, Fanelli G. Opioid risk addiction in the management of chronic pain in primary care: the addition risk questionnaire. Eur Rev Med Pharmacol Sci. 2015;19:4898-4905.

21. Hah JM, Sharifzadeh Y, Wang BM, et al. Factors associated with opioid use in a cohort of patients presenting for surgery. Pain Res Treat. 2015;2015:829696.

22. Menendez ME, Ring D, Bateman BT. Preoperative opioid misuse is associated with increased morbidity and mortality after elective orthopaedic surgery. Clin Orthop Relat Res. 2015;473:2402-2412.

23. Pulley DD. Preoperative evaluation of the patient with substance use disorder and perioperative considerations. Anesthesiol Clin. 2016;34: 201-211.

24. Carroll IR, Angst MS, Clark JD. Management of perioperative pain in patients chronically consuming opioids. Reg Anesth Pain Med. 2004; 29:576-591

25. Devin CJ, Lee DS, Armaghani SJ, et al. Approach to pain management in chronic opioid users undergoing orthopaedic surgery. $J$ Am Acad Orthop Surg. 2014;22:614-622.

26. Alford DP, Compton P, Samet JH. Acute pain management for patients receiving maintenance methadone or buprenorphine therapy. Ann Intern Med. 2006;144(2):127-134.

27. Merrill JO, Rhodes LA, Deyo RA, Marlatt GA, Bradley KA. Mutual mistrust in the medical care of drug users: the keys to the "narc" cabinet. J Gen Intern Med. 2002;17:327-333.

28. van Boekel LC, Brouwersa EPM, van Weeghela J, Garretsen HFL. Stigma among health professionals towards patients with substance use disorders and its consequences for healthcare delivery: systematic review. Drug Alcohol Depend. 2013;131(1-2):23-35.

29. Eyler ECH. Chronic and acute pain and pain management for patients in methadone maintenance treatment. Am J Addict. 2013;22:75-83.

30. Mao J. Opioid-induced abnormal pain sensitivity: implications in clinical opioid therapy. Pain. 2002;100:213-217.

31. Chapman CR, Donaldson G, Davis J, et al. Postoperative pain patterns in chronic pain patients: a pilot study. Pain Med. 2009;10: 481-487.

32. Compton P, Charuvastra VC, Kintaudi K, Ling W. Pain responses in methadone-maintained opioid abusers. J Pain Symptom Manage. 2000; 20:237-245.

33. Manfredi PL, Gonzales GR, Cheville AL, Kornick C, Payne R. Methadone analgesia in cancer pain patients on chronic methadone maintenance therapy. J Pain Symptom Manage. 2001;21(2):169-174.

34. Kantor TG, Cantor R, Tom E. A study of hospitalized surgical patients on methadone maintenance. Drug Alcohol Depend. 1980;6(3):163-173.

35. Oliver J, Coggins C, Compton P, et al. American Society for Pain Management Nursing position statement: pain management in patients with substance use disorders. J Addict Nurs. 2012;23(3):210-222.

36. Huxtable CA, Roberts LJ, Somogyi AA, MacIntyre PE. Acute pain management in opioidtolerant patients: a growing challenge. Anaesth Intensive Care. 2011;39(5):804-823.

37. Paschkis Z, Potter ML. Acute pain management for inpatients with opioid use disorder. Am J Nurs. 2015;115(9):24-32.

38. Shah S, Kapoor S, Durkin B. Analgesic management of acute pain in the opioid-tolerant patient. Curr Opin Anesthesiol. 2015;28:398-402.

39. Sen S, Arulkumar S, Cornett EM, et al. New pain management options for the surgical patient on methadone and buprenorphine. Curr Pain Headache Rep. 2016;20(3):16. 
40. Sacerdote P, Coluzzi F, Fanelli A. Sublingual sufentanil, a new opportunity for the improvement of postoperative pain management in Italy. Eur Rev Med Pharmacol Sci. 2016;20(7):1411-1422.

41. Eipe N, Penning J. Opioid conversions and patient-controlled analgesia parameters in opioid-dependent patients. Can J Anesth. 2010;57: 1129-1130.

42. Fanelli A, Ruggeri M, Basile M, et al. Activity-based costing analysis of the analgesic treatments used in postoperative pain management in Italy. Minerva Med. 2016;107(1):1-13.

43. Coluzzi F, Mattia C, Savoia G, et al. Postoperative pain surveys in Italy from 2006 and 2012: (POPSI and POPSI-2). Eur Rev Med Pharmacol Sci. 2015;19(22):4261-4269.

44. Meissner W, Coluzzi F, Fletcher D, et al. Improving the management of post-operative acute pain: priorities for change. Curr Med Res Opin. 2015;31(11):2131-2143.

45. Lewis NL, Williams JE. Acute pain management in patients receiving opioids for chronic and cancer pain. Contin Educ Anaesth Crit Care Pain. 2005;5(4):127-129.

46. Hadi I, Morley Forster PK, Dain S, Horrill K, Moulin DE. Brief review: perioperative management of the patient with chronic non-cancer pain. Can J Anaesth. 2006;53:1190-1199.

47. Oppermann J, Bredow J, Spies CK, et al. Effect of prolonged-released oxycodone/naloxone in postoperative pain management after total knee replacement: a nonrandomized prospective trial. J Clin Anesth. 2016; 33:491-497.

48. Richebé P, Beaulieu P. Perioperative pain management in the patient treated with opioids: continuing professional development. Can J Anesth. 2009;56:969-981.

49. Stromer W, Michaeli K, Sandner-Kiesling A. Perioperative pain therapy in opioid abuse. Eur J Anesthesiol. 2013;30:55-64.

50. Daccache G, Jeanne M, Fletcher D. The analgesia nociceptionindex: tailoring opioid administration. Anesth Analg. 2017;125(1):15-17.

51. Carrol IR, Angst MS, Clark JD. Management of perioperative pain in patients chronically consuming opioids. Reg Anesth Pain Med. 2004;29: 576-591.

52. de Leon-Casasola OA, Myers DP, Donaparthi S, et al. A comparison of postoperative epidural analgesia between patients with chronic cancer taking high doses of oral opioids versus opioid-naive patients. Anesth Analg. 1993;76(2):302-307.
53. Huxtable CA, Roberts LJ, Somogyi AA, MacIntyre PE. Acute pain management in opioid-tolerant patients: a growing challenge. Anaesth Intensive Care. 2011;39(5):804-823.

54. Schuckit MA. Treatment of opioid-use disorders. N Engl J Med. 2016; 375(4):357-368.

55. Yaksh TL, Wallace MS. Opioids, analgesia, and pain management. In: Brunton L, Chabner B, Knollman B, editors. Goodman \& Gilman's the Pharmacological Basis of Therapeutics. 12th ed. New York: McGraw-Hill; 2011:481-525.

56. Fonseca F, de la Torre R, Díaz L, et al. Contribution of cytochrome P450 and ABCB1 genetic variability on methadone pharmacokinetics, dose requirements. Response. PLoS One. 2011;6(5):e19527.

57. McCance-Katz EF, Sullivan LE, Nallani S. Drug interactions of clinical importance among the opioids, methadone and buprenorphine, and other frequently prescribed medications: a review. Am J Addict. 2010; 19:4-16.

58. Walker PW, Palla S, Pei BL, et al. Switching from methadone to a different opioid: what is the equianalgesic dose ratio? J Palliat Med. 2008;11(8):1103-1108.

59. Lutfy K, Cowan A. Buprenorphine: a unique drug with complex pharmacology. Curr Neuropharmacol. 2004;2:395-402.

60. Orman JS, Keating GM. Buprenorphine/naloxone: a review of its use in the treatment of opioid dependence. Drugs. 2009;69(5):577-607.

61. Bryson EO. The perioperative management of patients maintained on medications used to manage opioid addiction. Curr Opin Anesthesiol. 2014;27:359-364

62. Krupitsky E, Nunes EV, Ling W, Gastfriend DR, Memisoglu A, Silverman BL. Injectable extended-release naltrexone (XR-NTX) for opioid dependence: long-term safety and effectiveness. Addiction. 2013; 108(9):1628-1637.

63. Curatolo C, Trinh M. Challenges in the perioperative management of the patient receiving extended-release naltrexone. AA Case Rep. 2014; 3(11):142-144.

64. Dunbar JL, Turncliff RZ, Dong Q, Silverman BL, Ehrich EW, Lasseter KC. Single- and multiple-dose pharmacokinetics of long-acting injectable naltrexone. Alcohol Clin Exp Res. 2006;30(3):480-490.
Therapeutics and Clinical Risk Management

\section{Publish your work in this journal}

Therapeutics and Clinical Risk Management is an international, peerreviewed journal of clinical therapeutics and risk management, focusing on concise rapid reporting of clinical studies in all therapeutic areas, outcomes, safety, and programs for the effective, safe, and sustained use of medicines. This journal is indexed on PubMed Central, CAS,

\section{Dovepress}

EMBase, Scopus and the Elsevier Bibliographic databases. The manuscript management system is completely online and includes a very quick and fair peer-review system, which is all easy to use. Visit http://www.dovepress.com/testimonials.php to read real quotes from published authors. 